\title{
Perceived Benefits of Implantable Cardioverter Defibrillator Implantation among Heart Failure Patients and Its Relation to Quality of Life: A Cross-Sectional Study
}

\author{
Kevser Gülcihan Balci · Mustafa Mücahit Balci · Mehmet Kadri Akboğa • \\ Fatih Sen · Burak Açar · Samet Yılmaz • Emek Ediboğlu • \\ Orhan Maden · Hatice Selcuk · Mehmet Timur Selcuk · Ahmet Temizhan • \\ Sinan Aydoğdu \\ To view enhanced content go to www.cardiologytherapy-open.com \\ Received: May 23, 2015 / Published online: September 14, 2015 \\ (C) The Author(s) 2015. This article is published with open access at Springerlink.com
}

\section{ABSTRACT}

Introduction: Patients with heart failure (HF) and implantable cardioverter defibrillators (ICDs) may misunderstand the indication of ICDs due to unsatisfactory information. The goal of this study is to evaluate the patient perspective of ICD indication and its relation to quality of life, as well as to identify probable communication gaps between doctors and ICD receivers.

Methods: A total of 119 patients with HF who were implanted with a single-chamber ICD were evaluated in outpatient clinics. Patients with cardiac resynchronization therapy-defibrillators

Electronic supplementary material The online version of this article (doi:10.1007/s40119-015-0049-8) contains supplementary material, which is available to authorized users.

K. G. Balci $(\bowtie) \cdot$ M. M. Balci · M. K. Akboğa ·

F. Sen · B. Açar · S. Yılmaz · E. Ediboğlu .

O. Maden - H. Selcuk - M. T. Selcuk - A. Temizhan ·

S. Aydoğdu

Turkiye Yuksek Ihtisas Research and Education

Hospital, Ankara, Turkey

e-mail: kevs84@gmail.com were not included in the study. In a questionnaire, patients were asked about the indication of the ICD procedure and classified according to the perceived benefits.

Results: This study showed that most of the patients ( $n=92,77.3 \%)$ believed that ICD was implanted for improvement of heart dysfunction or for symptom relief. According to the perceived benefit groups, physical function, general health, vitality, and role physical scores were significantly lower in the symptom relief group $(p<0.05)$.

Conclusion: Patients with HF and ICD mostly believed that the cardioverter defibrillator implanted for improving heart function or symptom relief. Doctors play a significant role when a patient is first referred for ICD because less-informed patients are more prone to misunderstand the procedure's benefits. Moreover, unfulfilled expectations may lead to loss of confidence in applied therapies and result in poor health outcomes.

Keywords: Heart failure; Implantable cardioverter defibrillator; Perception; Quality of life 


\section{INTRODUCTION}

Since the first introduction of implantable cardioverter defibrillator (ICD) treatment in 1985 [1], recipients of this treatment have rapidly increased [2]. Patients who have either experienced serious abnormal heart rhythms or are under risk of sudden cardiac death (SCD) benefit from ICD treatment, which has been proven to prolong survival in such patients [3]. Being at risk of lethal arrhythmias due to reduced left ventricular ejection fraction (EF) and structurally abnormal myocardium, nearly one-third of ICD receivers are heart failure (HF) patients [4]. Therefore, either for primary or secondary prevention, current guidelines recommend ICD implantation in patients with left ventricular disfunction due to prior myocardial infarction or nonischemic cardiomyopathy $[5,6]$.

ICDs prevent arrhythmic deaths, but they also affect quality of life (QOL) because of device-related problems [7]. Most patients experience electric shocks, pain, and adaptation problems in life after discharge [8]. Because they are given limited information about probable problems related to ICDs, patients feel anxiety, depression, fear, and stress when they undergo ICD treatment [9]. If patients are better informed and more engaged in treatment decisions, they will have more opportunities to adhere to treatment requirements by choosing the best-fitted treatment to their lifestyle, which positively impacts their health outcomes [10]. Patient perceptions of ICD benefits are also important because misunderstandings may cause unfulfilled expectations, loss of confidence in one's doctor, and lack of adherence to medical treatment. Older and less-educated patients commonly have higher rates of hospitalization, poorer health outcomes, and increased mortality [11-13]. Therefore, education level-based information may improve health outcomes [10]. Moreover, explaining risks and benefits in an understandable way allows patients to participate in the decision-making process by making informed choices [14].

The goals of this study were to evaluate patient perceptions of ICD implantation indication and its relation to QOL.

\section{METHODS}

\section{Participants}

Patients with $\mathrm{HF} \quad(\mathrm{EF}<30)$ and implanted single-chamber ICD for primary or secondary prevention of SCD were evaluated during routine controls in outpatient clinics and answered a questionnaire. Patients with cardiac resynchronization therapy-defibrillators and ICD without HF and who were unable to answer the questionnaire because of cooperation problems were not included in the study. The interviewer scheduled meetings at times that were convenient to patients. Each interview lasted approximately $20 \mathrm{~min}$.

\section{Questionnaire}

A questionnaire consisting of open-ended questions was given to patients during routine controls in outpatient clinics. All patients were asked about the indication of their ICD procedure in simple terms and uncomplicated language. Uneducated patients answered the questionnaire with the help of an educated relative or a doctor without any manipulation. After a short conversation about their disease, education level, and ICD-related limitations after the procedure, the simple question, 
"What do you think about why this device was implanted?" was asked to understand patients' perspectives regarding the ICD indication. Before the current study was started, a list of potential benefits (save life, arrhythmia termination, symptom relief, and improve heart function/treat cardiac pump failure) that had already been reported by the patients in outpatient clinics was reviewed and then adopted to our study design according to a prior research [15]. To identify patient satisfaction following ICD implantation, the question, "Did this treatment fulfill your expectations?" was asked, and yes/no answers were noted by the interviewer.

QOL was measured by the Medical Outcomes Study Form 36 (SF-36), which is composed of eight subscales that reflect physical functioning, role physical, bodily pain, general health, vitality, social functioning, role emotional, and mental functioning [16]. Scores ranging from 0 to 100 were obtained, and higher scores indicate better functioning with fewer problems. All patients filled out a form to evaluate the post-procedural QOL. The New York Heart Association (NYHA) functional class was used to assess the severity of HF symptoms. Electronic medical records were also used to obtain participants' medical histories.

\section{Statistical Analysis}

The statistical analysis was conducted using the SPSS for Windows 15.0 program (SPSS Inc., Chicago, IL, US). Continuous variables are presented as the mean \pm standard deviation where applicable. Nominal data were analyzed by Pearson's Chi-square test. The differences in mean values between two groups were compared by the independent $t$ test and Mann-Whitney $U$ test, depending on the fulfillment of assumptions for the tests. If there were more than two groups, mean values were compared by the $F$ test or Kruskal-Wallis test, depending on the fulfillment of assumptions for the tests. The degree of association between continuous variables was evaluated by Pearson correlation analyses.

Whether the statistically significant effect of major clinical measurements on satisfaction and misunderstanding the ICD procedure were continuing or not was evaluated by Binary Logistic Regression analysis after adjustment for all possible risk factors. Any variable whose univariable test had a $p$ value $<0.05$ was accepted as a candidate for the multivariable model along with all variables of known clinical importance. Adjusted odds ratios (OR), 95\% confidence intervals (CI) and wald statistics were calculated for each variable. The optimal cutoff points of the differences in age to determine the misunderstanding the ICD procedure were evaluated by ROC analysis calculating area under the curve as giving the maximum sum of sensitivity and specificity for the significant test. Sensitivity, specificity, positive and negative predictive values were also calculated at the best cutoff point for the differences in age.

A $p$ value less than 0.05 was considered statistically significant.

\section{Compliance with Ethics Guidelines}

Informed consent was obtained from all individual participants included in the study, and the study protocol was approved by the hospital ethics committee.

All procedures followed were in accordance with the ethical standards of the responsible committee on human experimentation 
(institutional and national) and with the Helsinki Declaration of 1964, as revised in 2013. Informed consent was obtained from all patients for being included in the study.

\section{RESULTS}

\section{Baseline Characteristics}

The mean age of participants $(N=119)$ was $60.13 \pm 11.5$ years; most $(85.7 \%)$ were men, most $(73.1 \%)$ were married, and most $(70.6 \%)$ had ischemic HF. Indication for ICD implantation was mostly for primary prevention (67.2\%). The mean time between ICD implantation date and the control visit was $3.03 \pm 1.3$ years and the median time between first diagnosis of HF and ICD implantation was 18 (13-29) months. The baseline mean EF was $24.95 \% \pm 5.15 \%$; most of the patients $(89.1 \%)$ were in NYHA class 1 and 2, and most (36.1\%) had graduated from primary school. Of these patients in the primary prevention group 4 (5\%) of them experienced improvement in heart functions, in the secondary prevention group no improvement in EF was observed. Among patients, 43 (36.1\%) of them experienced shock during the last 6 months, $68(57.1 \%)$ of them said that ICD implantation fulfilled their expectations. In the perceived benefit groups, 45 patients $(37.8 \%)$ were in the symptom relief group, 27 patients $(22.7 \%)$ were in the arrhythmia termination/save life group, and 47 patients (39.5\%) were in the improvement of heart dysfunction group (Table 1). ROC curve analysis was used to determine the relation between age and misunderstanding the ICD procedure. The area under the curve was 0.739 for age $>58.5$ years $(95 \%$ CI $0.632-0.845$, $p<0.001)$. Age $>58.5$ years predicted misunderstanding the procedure with a specificity $62.5 \%$ and a sensitivity $72.6 \%$. In binary logistic regression analysis, only low education (uneducated, primary and middle school) showed a significant association with misunderstanding the ICD procedure $(\mathrm{OR}=4.932 ; 95 \%$ CI $1.468-16.569, p=0.010)$.

\section{Perceived Benefits}

There was a significant difference in the perceived benefit groups according to education level. The education level of patients in the arrhythmia termination/save life group was higher than patients in other groups; these patients were also more likely to be younger than those in other groups. This implies that low-educated patients were likely to be older and believe that ICD implantation was done for improvement of heart dysfunction or symptom relief $(p<0.001)$. In comparison with the primary prevention group, patients in the secondary prevention group were likely to believe that ICD implanted for arrhythmia termination or for saving life $(p<0.001)$. According to the NYHA functional classes, there was no significant difference in the perceived benefit groups $(p=0.757)$. Female patients were more likely to believe that ICD implantation would improve symptoms $(p=0.044)$, whereas male patients were more likely to think that implantation would improve heart functions $(p=0.045)$ (Table 1$)$.

\section{QOL}

Among patients, QOL was best for mental health (74) and worst for general health (40). Unmarried patients' mental health was significantly higher than those who were married; other QOL scores did not differ according to marital status or gender $(p>0.05)$. Also, there was no significant difference in QOL scores between the primary 
Table 1 Demographic and clinical data

\begin{tabular}{|c|c|c|c|c|c|}
\hline Variables & $\begin{array}{l}\text { All patients } \\
(n=119)\end{array}$ & $\begin{array}{l}\text { Symptom } \\
\text { relief }(n: 45)\end{array}$ & $\begin{array}{l}\text { Arrhythmia termination/ } \\
\text { save life }(n: 27)\end{array}$ & $\begin{array}{l}\text { Improve heart } \\
\text { function }(n: 47)\end{array}$ & $p$ value \\
\hline Age & $60.13 \pm 11.5$ & $63.74 \pm 9.15$ & $52.67 \pm 11.70$ & $60.89 \pm 11.78$ & $<0.001$ \\
\hline Sex & & & & & $<0.001$ \\
\hline Male & $102(85.7 \%)$ & $35(77.8 \%)$ & $23(85.2 \%)$ & $44(93.6 \%)$ & 0.045 \\
\hline Female & $17(14.3 \%)$ & $10(22.2 \%)$ & $4(14.8 \%)$ & $3(6.4 \%)$ & 0.044 \\
\hline Marital status & & & & & 0.736 \\
\hline Married & $87(73.1 \%)$ & $32(71.1 \%)$ & $20(74.1 \%)$ & $35(74.5 \%)$ & \\
\hline $\begin{array}{l}\text { Unmarried/divorced/ } \\
\text { widowed }\end{array}$ & $32(26.9 \%)$ & $13(28.9 \%)$ & 7 (25.9\%) & $12(25.5 \%)$ & \\
\hline Education level & & & & & $<0.001$ \\
\hline Uneducated & $30(25.2 \%)$ & $15(33.3 \%)$ & $2(7.4 \%)$ & $13(27.7 \%)$ & \\
\hline Primary school & $43(36.1 \%)$ & $14(31.1 \%)$ & $8(29.6 \%)$ & $21(44.7 \%)$ & \\
\hline Middle school & $23(19.3 \%)$ & $13(28.9 \%)$ & $4(14.8 \%)$ & $6(12.8 \%)$ & \\
\hline $\begin{array}{l}\text { High school/ } \\
\text { university }\end{array}$ & $23(19.3 \%)$ & $3(6.7 \%)$ & $13(48.1 \%)$ & $7(14.9 \%)$ & \\
\hline Etiology & & & & & 0.079 \\
\hline Ischemic & $84(70.6 \%)$ & $37(82.2 \%)$ & $15(55.6 \%)$ & $32(68.1 \%)$ & \\
\hline Primary prevention & $80(67.2 \%)$ & $35(77.8 \%)$ & $8(29.6 \%)$ & $37(78.7 \%)$ & $>0.05$ \\
\hline Secondary prevention & $39(32.8 \%)$ & $10(22.2 \%)$ & $19(70.4 \%)$ & $10(21.3 \%)$ & $<0.001$ \\
\hline LVEF (\%) & $24.95 \pm 5.15$ & $24.24 \pm 5.21$ & $24.59 \pm 4.42$ & $25.83 \pm 5.44$ & 0.253 \\
\hline $\begin{array}{l}\text { NYHA functional } \\
\text { class }\end{array}$ & & & & & 0.757 \\
\hline NYHA 1-2 & $106(89.1 \%)$ & $40(88.9 \%)$ & $24(88.9 \%)$ & $42(89.4 \%)$ & \\
\hline NYHA 3-4 & $13(10.9 \%)$ & $5(11.1 \%)$ & $3(11.1 \%)$ & $5(10.6 \%)$ & \\
\hline ICD shock & & & & & 0.559 \\
\hline+ & $43(36.1 \%)$ & $14(31.1 \%)$ & $11(40.7 \%)$ & $18(38.3 \%)$ & \\
\hline Satisfied after ICD & & & & & 0.727 \\
\hline Yes & $68(57.1 \%)$ & $24(53.3 \%)$ & $17(63.0 \%)$ & $27(57.4 \%)$ & \\
\hline
\end{tabular}

$L V E F$ left ventricular ejection fraction, NYHA New York Heart Association, ICD implantable cardioverter defibrillators

and secondary prevention groups $(p>0.05)$. According to the perceived benefit groups, physical function, general health, vitality, and role physical scores were significantly lower in the symptom relief group $(p<0.005)$ (Fig. 1). Bodily pain scores were significantly lower in the shock received group $(p<0.001)$ (Fig. 2). Except for mental health scores, all scores were 
Fig. 1 Difference in quality of life scores according to the perceived benefit groups

Fig. 2 Bodily pain score difference according to the implantable cardioverter defibrillator (ICD) shock
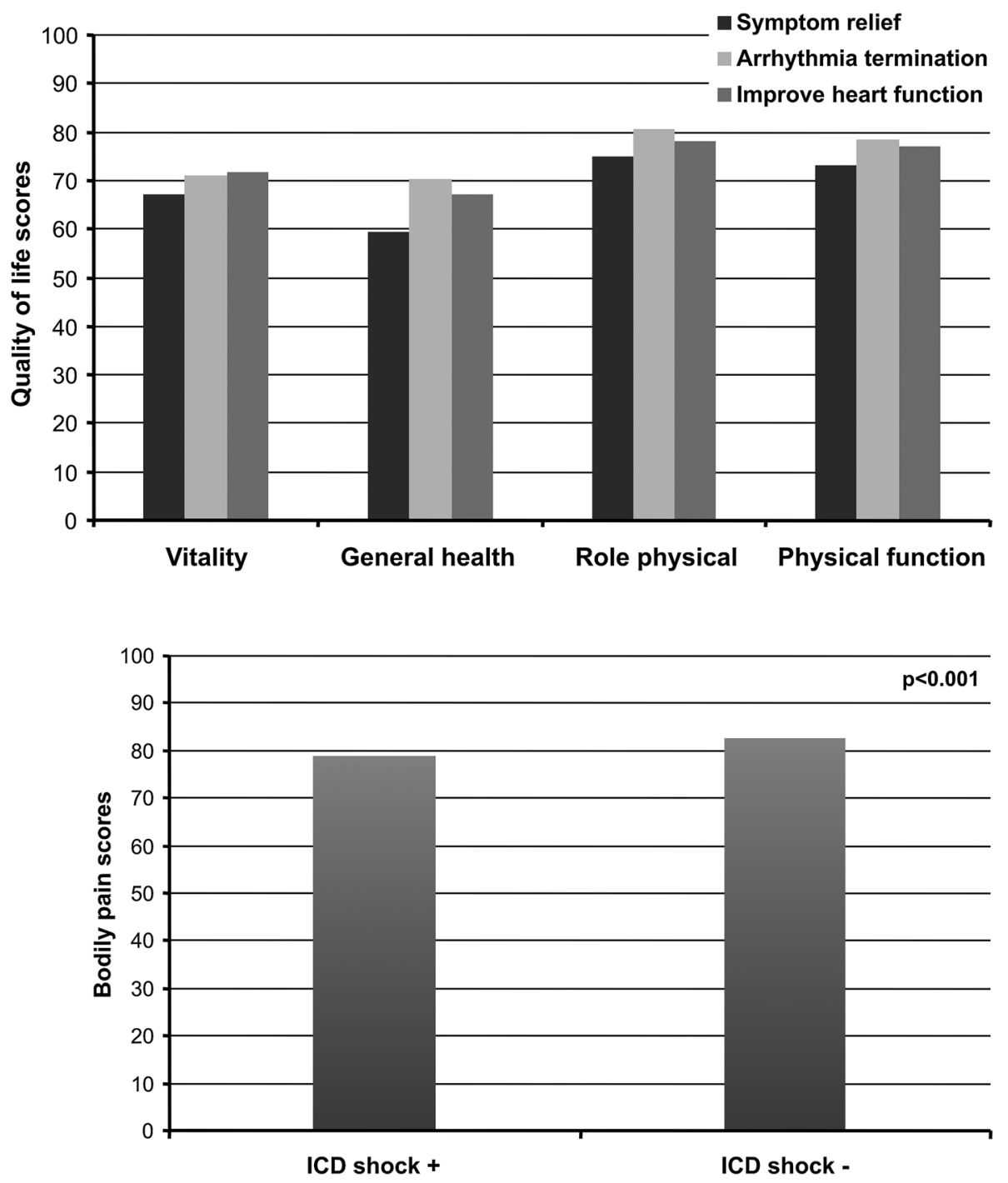

significantly lower in the NYHA class 3 and 4 groups when compared to NYHA class 1 and 2 groups $(p<0.05)$. According to the improvement in EF role physical, physical functioning and mental functioning scores were significantly higher in the improvement + group.

\section{Satisfaction after ICD}

There was no significant difference in satisfaction after ICD according to perceived benefits and improvement in EF $(p>0.05)$
(Table 2). In the correlation analysis, there was no significant correlation between satisfaction after ICD groups and perceived benefit groups. Furthermore, there was no significant correlation between satisfaction after ICD groups and NYHA functional classes. Binary logistic regression analysis of the variables is shown in Table 3. Only NYHA showed a strong association with satisfaction after ICD implantation $\quad(\mathrm{OR}=11.872, \quad p<0.001)$. Patients with worse functional capacity were not satisfied with ICD implantation. 
Table 2 Comparison of the quality of life scores according to the ejection fraction (EF) improvement after 1 year of implantable cardioverter defibrillators implantation

\begin{tabular}{llll}
\hline Variables & \multicolumn{2}{l}{ Improvement in EF } & \multirow{2}{*}{$\boldsymbol{p}$ value } \\
\cline { 2 - 3 } & $\boldsymbol{+}$ & - & 0.016 \\
\hline Role physical & $84(80-90)$ & $76(65-95)$ & 0.005 \\
Physical functioning & $86(80-88)$ & $75(60-90)$ & 0.026 \\
Mental functioning & $89(85-92)$ & $85(74-100)$ & 0.079 \\
Satisfaction + (no. of patients) & $3 / 4$ & $65 / 115$ & \\
\hline
\end{tabular}

Table 3 Odds ratio for satisfaction in multivariate regression analysis

\begin{tabular}{|c|c|c|c|c|}
\hline \multirow[t]{2}{*}{ Variables } & \multirow[t]{2}{*}{ Odds ratio } & \multicolumn{2}{|c|}{$95 \%$ confidence interval } & \multirow[t]{2}{*}{$p$ value } \\
\hline & & Lower & Upper & \\
\hline Hypertension & 1.953 & 0.508 & 7.508 & 0.330 \\
\hline NYHA & 11.872 & 3.697 & 38.124 & $<0.001$ \\
\hline Secondary prevention & 4.542 & 0.981 & 21.032 & 0.053 \\
\hline No smoking & 1.723 & 0.431 & 8.892 & 0.442 \\
\hline Arrhythmia termination/saving life & 2.414 & 0.404 & 14.423 & 0.334 \\
\hline
\end{tabular}

\section{DISCUSSION}

The main findings of the present study were: (1) patients were most likely to think that the ICD was implanted for improvement of heart functions or for symptom relief, and these patients were mostly low educated and older; (2) patients who were given ICD treatment for secondary prevention had more accurate perceptions of ICD indication when compared to patients who were given ICD treatment for primary prevention; and (3) in the symptom relief group, physical function, general health, vitality, and role physical scores were significantly lower than in the other perceived benefit groups.

ICD prevents arrhythmic deaths, but HF progresses in the course of time. What the patient knows about the prognosis of the disease is essential, not only for making medical decisions, but also for anticipated benefits of applied therapies. A study conducted by Allen et al. showed that HF patients had survival expectations that differed from the expected natural history of the disease [17]. Optimistic estimates of ICD efficacy [18, 19] and patient uncertainty about the indication of implantation were reported [19]. As QOL is equally important as the longevity of life [20], patients may hope for ameliorated heart dysfunction and a less restricted life. In our study, we observed that four subscales of QOL were significantly lower in the symptom relief group than the other perceived benefit groups. Although there was not a significant difference in the perceived benefit groups according to NYHA functional classes, QOL as measured by the SF-36 may give a better 
expression of disease severity and patients' physical restrictions. Another explanation for this finding is that patients with worse physical function, general health, vitality, and role physical scores might expect too much from applied therapies (i.e., that their symptoms will be fully relieved). In our study, an optimistic outlook about the disease prognosis may be responsible for these results. Limited or complicated information given to patients before ICD implantation may produce incorrect perceptions regarding the procedure.

Although we did not observe a significant correlation between satisfaction after ICD implantation and perceived benefit groups, over $50 \%$ of patients reported being satisfied after the procedure. The reason for this finding may be due to patients' feeling safer with a device [9], regardless of whether they know the exact benefits of ICD. One noteworthy finding is that in the secondary prevention group, more accurate perceptions of ICD indication were observed. Patients who have previously faced a serious arrhythmic event might be more aware of the risks of lethal arrhythmias and more likely to seek out information about the ICD indication from their clinicians.

Several studies have investigated the doctor-patient communication gaps after a patient had received an ICD $[9,14,19,21$, 22]. Agad et al. observed that none of the patients in their study were given information about alternative treatment options or the estimated risk of a fatal arrhythmia. They reported that patients felt that the decision was too complex for them to make on their own [9]. Due to the improvement of ICD devices, the length of hospital stays after implantation has been reduced, and thus, so has the delivery of detailed information [21, 23]. Nurses spend greater time with patients than do clinicians [24]; previous research has revealed an improvement in many subscales of QOL in ICD recipients who had implemented an education and nurse follow-up program [21]. Hence, health care professionals including nurses should involve patients in their own treatment decisions and provide detailed information about any planned or applied therapies. Therefore, during their hospital stay, nurses should take an active role in informing ICD patients so they can be provided with better health outcomes.

Previously, Kureshi et al. reported a difference in perceptions of patients with stable coronary artery disease who underwent elective percutaneous coronary intervention (PCI) according to the patients' age and education levels. They found that the informed consent process allowed for patients to review the benefits, risks, and alternatives associated with PCI [15]. Informed consent materials developed for all literacy levels generate better results in overall health outcomes [25]. When compared to highly educated patients, physicians are less likely to ask less-educated patients for their preferences [26]. Furthermore, Arora et al. reported that older and less-educated patients preferred to leave their medical decisions to their physicians rather than take an active role [27]. Probably because of the former, when compared to younger patients, those who are older tend to be less knowledgeable about their ICD [28]. Ethically, clinicians have an obligation to obtain informed consent from all patients [10]. The oldest, sickest, and least-educated patients are among the most disadvantaged; clinicians should go above and beyond to help these patients participate in their own treatment decisions. 


\section{Limitations}

The main limitations of this study include having a small sample size and cross-sectional design. Also, the study cohort consisted of mostly low-educated patients; more educated patients may be more aware of the indication of the ICD procedure. In addition, we did not interview the operators and referring physicians to exclude doctor-related misperceptions. Also, the time interval between when the patient was first informed about the procedure and when the patient underwent ICD implantation was not evaluated. Patients who have enough time to contemplate the advantages and disadvantages of the procedure may more accurately understand the benefits of ICD. Another limitation is that we did not interview any patients who refused to have an ICD, so we do not know if these patients have more valid perceptions regarding the ICD procedure. Lastly, because of the cross-sectional design of the study, only post-procedural assessments of QOL were provided; we were not able to evaluate the pre-procedural QOL, which may lead to an interpretation bias.

\section{CONCLUSION}

In this study, patients with HF and ICD were most likely to believe that the ICD implanted for the purpose of improving heart function or for symptom relief. This finding was mostly evident in the primary prevention group. Patients in the secondary prevention group were more accurately informed about the indication of device implantation. This is likely due to the fact that these patients had previously experienced arrhythmia, and they also may have received greater explanations from clinicians. In our opinion, doctors play a significant role when a patient is first referred for ICD implantation because less-informed patients are more prone to misunderstand the procedure's benefits. Moreover, unfulfilled expectations may lead to loss of confidence in applied therapies and result in poor health outcomes.

\section{ACKNOWLEDGMENTS}

No funding or sponsorship was received for this study or publication of this article. All named authors meet the International Committee of Medical Journal Editors (ICMJE) criteria for authorship for this manuscript, take responsibility for the integrity of the work as a whole, and have given final approval for the version to be published.

Conflict of Interest. K.G. Balci, M.M. Balci, M.K. Akboğa, F. Sen, B. Açar, S. Yılmaz, E. Ediboğlu, O. Maden, H. Selcuk, M.T. Selcuk, A. Temizhan and S. Aydoğdu have no disclosures to declare.

\section{Compliance with Ethics} Guidelines. Informed consent was obtained from all individual participants included in the study, and the study protocol was approved by the hospital ethics committee. All procedures followed were in accordance with the ethical standards of the responsible committee on human experimentation (institutional and national) and with the Helsinki Declaration of 1964, as revised in 2013. Informed consent was obtained from all patients for being included in the study. 
Open Access. This article is distributed under the terms of the Creative Commons Attribution-NonCommercial 4.0 International License (http://creativecommons.org/licenses/ by-nc/4.0/), which permits any noncommercial use, distribution, and reproduction in any medium, provided you give appropriate credit to the original author(s) and the source, provide a link to the Creative Commons license, and indicate if changes were made.

\section{REFERENCES}

1. Hauer RN, Aliot E, Block M, et al. Indications for implantable cardioverter defibrillator (ICD) therapy. Europace. 2001;3:169-76.

2. National Institute for Health and Clinical Excellence. Chronic heart failure: National clinical guideline for diagnosis and management in primary and secondary care: partial update 2010. National Clinical Guideline Centre, NICE, London. http://www.ncbi.nlm.nih.gov/books/n/nicecollect/. Accessesed Aug 2010.

3. Reiffel JA, Dizon J. The implantable cardioverter-defibrillator: patient perspective. Circulation. 2002;105:1022-4.

4. Glikson M, Friedman PA. The implantable cardioverter defibrillator. Lancet. 2001;357:1107-17.

5. McMurray JJ, Adamopoulos S, Anker SD, et al. ESC guidelines for the diagnosis and treatment of acute and chronic heart failure 2012: the task force for the diagnosis and treatment of Acute and chronic heart failure 2012 of the european society of cardiology. Developed in collaboration with the heart failure association (HFA) of the ESC. Eur J Heart Fail. 2012;14:803-69.

6. Hunt SA, Abraham WT, Chin MH, et al. 2009 Focused update incorporated into the ACC/AHA 2005 guidelines for the diagnosis and management of heart failure in adults: a report of the American college of cardiology foundation/American heart association task force on practice guidelines: developed in collaboration with the international society for heart and lung transplantation. Circulation. 2009;119:e391-479.

7. Pelletier D, Gallagher R, Mitten-Lewis S, et al. Australian implantable cardiac defibrillator recipients: quality-of-life issues. Int J Nurs Pract. 2002;8:68-74.

8. Zayac S, Finch N. Recipients' of implanted cardioverter-defibrillators actual and perceived adaptation: a review of the literature. J Am Acad Nurse Pract. 2009;21:549-56.

9. Agård A, Löfmark R, Edvardsson $\mathrm{N}$, et al. Views of patients with heart failure about their role in the decision to start implantable cardioverter defibrillator treatment: prescription rather than participation. J Med Ethics. 2007;33:514-8.

10. King JS, Eckman MH, Moulton BW. The potential of shared decision making to reduce health disparities. J Law Med Ethics. 2011;39(Suppl 1):30-3.

11. Dewalt DA, Berkman ND, Sheridan S, et al. Literacy and health outcomes: a systematic review of the literature. J Gen Intern Med. 2004;19:1228-39.

12. Weiss BD, Hart G, McGee DL, et al. Health status of illiterate adults: relation between literacy and health status among persons with low literacy skills. J Am Board Fam Pract. 1992;5:257-64.

13. Baker DW, Wolf MS, Feinglass J, et al. Health literacy and mortality among elderly persons. Arch Intern Med. 2007;167:1503-9.

14. Sadarmin PP, Betts TR. Risk perception and implantable cardioverter defibrillators. Europace. 2012;14:3-4.

15. Kureshi F, Jones PG, Buchanan DM, et al. Variation in patients' perceptions of elective percutaneous coronary intervention in stable coronary artery disease: cross sectional study. BMJ. 2014;349:g5309.

16. Ware JE Jr, Sherbourne CD. The MOS 36-item short-form health survey (SF-36). I. Conceptual framework and item selection. Med Care. 1992;30:473-83.

17. Allen LA, Yager JE, Funk MJ, et al. Discordance between patient-predicted and model-predicted life expectancy among ambulatory patients with heart failure. JAMA. 2008;299:2533-42.

18. Stewart GC, Weintraub JR, Pratibhu PP, et al. Patient expectations from implantable defibrillators to prevent death in heart failure. J Card Fail. 2010;16:106-13.

19. Hauptman PJ, Chibnall JT, Guild C, et al. Patient perceptions, physician communication, and the implantable cardioverter-defibrillator. JAMA Intern Med. 2013;173:571-7.

20. Strachan PH, Carroll SL, de Laat S, et al. Patients' perspectives on end-of-life issues and implantable 
cardioverter defibrillators. J Palliat Care. 2011;27:6-11.

21. Cinar FI, Tosun N, Kose S. Evaluation of an education and follow-up programme for implantable cardioverter defibrillator-implanted patients. J Clin Nurs. 2013;22:2474-86.

22. Hill L, McIlfatrick S, Taylor B, et al. Patients' perception of implantable cardioverter defibrillator deactivation at the end of life. Palliat Med. 2015;29:310-23.

23. White E. Patients with implantable cardioverter defibrillators: transition to home. J Cardiovasc Nurs. 2000;14:42-52.

24. Epstein AE, Swarens A, Skadsen A, et al. Comparison of perception of health status by physicians, nurses, and patients in the dual-chamber and VVI implantable defibrillator (DAVID) trial. Am J Cardiol. 2004;93:120-1.
25. Eckman $\mathrm{MH}$, Wise R, Leonard AC, et al. Impact of health literacy on outcomes and effectiveness of an educational intervention in patients with chronic diseases. Patient Educ Couns. 2012;87:143-51.

26. Fagerlin A, Sepucha KR, Couper MP, et al. Patients' knowledge about 9 common health conditions: the decisions survey. Med Decis Mak. 2010;30(5 Suppl):35S-52S.

27. Arora NK. McHorney CAPatient preferences for medical decision making: who really wants to participate? Med Care. 2000;38:335-41.

28. Strömberg A, Fluur C, Miller J, et al. ICD recipients' understanding of ethical issues, ICD function, and practical consequences of withdrawing the ICD in the end-of-life. Pacing Clin Electrophysiol. 2014;37:834-42. 